\section{Cureus}

Received 12/08/2017

Review began 01/03/2018

Review ended 01/25/2018

Published 02/05/2018

\section{(c) Copyright 2018}

Korkmaz et al. This is an open access article distributed under the terms of the Creative Commons Attribution License CC-BY 3.0., which permits unrestricted use, distribution, and reproduction in any medium, provided the original author and source are credited.

\title{
Determining the Optimal Length and Safety of Pedicle Screws in the T12 Vertebra: A Morphometric Study
}

\author{
Mehmet F. Korkmaz ${ }^{1}$, Mehmet N. Erdem ${ }^{2}$, Huseyin Ozevren ${ }^{3}$, Reşit Sevimli ${ }^{4}$
}

1. Department of Orthopaedics and Traumatology, Inonu University School of Medicine, Malatya 2. Orthopaedics and Traumatology, Isik University, Istanbul, TUR 3. Department of Neurosurgery, Faculty of Medicine, Dicle University 4. Department of Orthopaedics and Traumatology, Inonu University School of Medicine, Malatya, TUR

$\square$ Corresponding author: Mehmet N.Erdem, mnerdem@yandex.com

Disclosures can be found in Additional Information at the end of the article

\section{Abstract}

Introduction: Despite the developments in implant technology and imaging methods and the advances in surgical techniques, there are still potential problems and complications of transpedicular screw application. This is a morphometric study to examine the proximity of the T12 vertebra to the thoracic aorta. Our aim was to define the appropriate length of the pedicle screw to be used in the $12^{\text {th }}$ thoracic vertebra, using computed tomography (CT) data.

Methods: Randomly selected cases from the same ethnic group in a specific age group were examined in terms of the length from the anterior vertebral body and the screw entry point of the T12 vertebra to the thoracic aorta. In light of these data, a statistical analysis was made for the selection of the most appropriate screw length.

Results: A statistically significant difference was detected in the distance from the T12 left screw entry point to the aorta between males and females $(p=0.001)$. No statistically significant correlation was found between age and the distance between the left screw entry point and the aorta ( $\mathrm{p}=0.105)$. Also, no statistically significant difference was detected between the T12 vertebral body-aorta distance in males and in females $(\mathrm{p}=0.212)$. The relationship between the shortest aorta-vertebral body distance and age was not statistically significant ( $p=0.7)$. Similarly, there was no statistically significant difference between the left screw entry pointaorta distance and the aorta-vertebral body shortest distance $(\mathrm{p}=0.731)$.

Conclusions: Significant differences were observed between males and females in terms of the distance between the T12 vertebra left screw entry point and the thoracic aorta $(\mathrm{p}=0.001)$. Thus, we can assert the need for the preoperative evaluation of patients with computed tomography in selecting the appropriate screw length and avoiding complications.

Categories: Orthopedics

Keywords: computed tomography, pedicle screw length, preoperative planning, t12 vertebra

\section{Introduction}

The spinal fixation method based on transpedicular screws was first described by Roy-Camille et al. [1]. Since 1963, the method has become more popular and a basic application of spinal fixation in recent years [2]. Despite the developments in implant technology and imaging

How to cite this article

Korkmaz M F, Erdem M N, Ozevren H, et al. (February 05, 2018) Determining the Optimal Length and Safety of Pedicle Screws in the T12 Vertebra: A Morphometric Study. Cureus 10(2): e2156. DOI $10.7759 /$ cureus. 2156 
methods over this time period and advances in surgical techniques, there are still potential problems and complications of transpedicular screw application [3]. Therefore, improvements in spinal fixation and healthy functional development of the pedicle screw system are important areas to be studied.

The thoracolumbar region is the area of transfer of biomechanical movement in the spine, therefore, it is the area where pathologies are seen most often. These pathologies include trauma, degenerative diseases, osteoporotic compression fractures, instabilities, neoplastic diseases, and infections [4]. The instrumentation of the thoracolumbar region with transpedicular screws is the most current and widespread choice in the treatment of these diseases.

The size of the screw should be determined by the compatibility of the entry point with the anatomical guides, such as the proximity of the thoracic aorta to the vertebral body and particularly at the level of the T12 vertebra. This is extremely important in preventing mortal complications, such as aorta injury.

Our aim in this study was to determine the optimum screw length by examining the T12 vertebra pedicle morphology with computed tomography (CT) and, thereby, to preoperatively calculate its depth.

\section{Materials And Methods}

The study was designed as a prospective, randomized, and morphometric study to examine the proximity of the T12 vertebra to the thoracic aorta using a CT scan. The CT sections of the T12 vertebrae of patients aged between 25 and 40 years who presented at the Emergency

Department or clinic, for whom a thoracic CT was requested for any possible pathology, were examined. The slices were obtained from only an Anatolian population. Patients with spinal deformity, tumor, fracture, infection, congenital anomaly, or history of surgery in the lumbar region were excluded. The study was completed with 30 males and 30 females who met the inclusion criteria and had a mean age of $31.9 \pm 3.9$ (range: 25 to 40 ) years.

First, axial images at 3-mm thickness were obtained. Following reconstruction in the bone window, the measurements of three images where the pedicle thickness was the greatest were taken, and the thickest measurement of the pedicle was selected from these images. Then, the distance between the screw entry point and the thoracic aorta and the distance between the anterior vertebral body and the thoracic aorta were digitally measured on this image with a magnetic resonance imaging (MRI) scanner (Leonardo Workstation Siemens, Siemens AG, Munich, Germany). Axial slices of 3-mm thickness from the thoracic vertebra were taken using a Philips MX 8000 CT unit (Philips Healthcare, Best, Netherlands) and examined.

Tomography images of the T12 vertebra were taken from the pedicle isthmus at 3-mm thickness (mid-pedicle slice) in the axial plane. The following parameters were examined on the CT slices: the distance between the screw entry point and the thoracic aorta and the distance between the anterior vertebral body and the thoracic aorta. For the length between the left screw entry point and the aorta, the measurement of the closest point of the T12 left screw entry point to the thoracic aorta was made (Figure 1 and Figure 2). 


\section{Cureus}

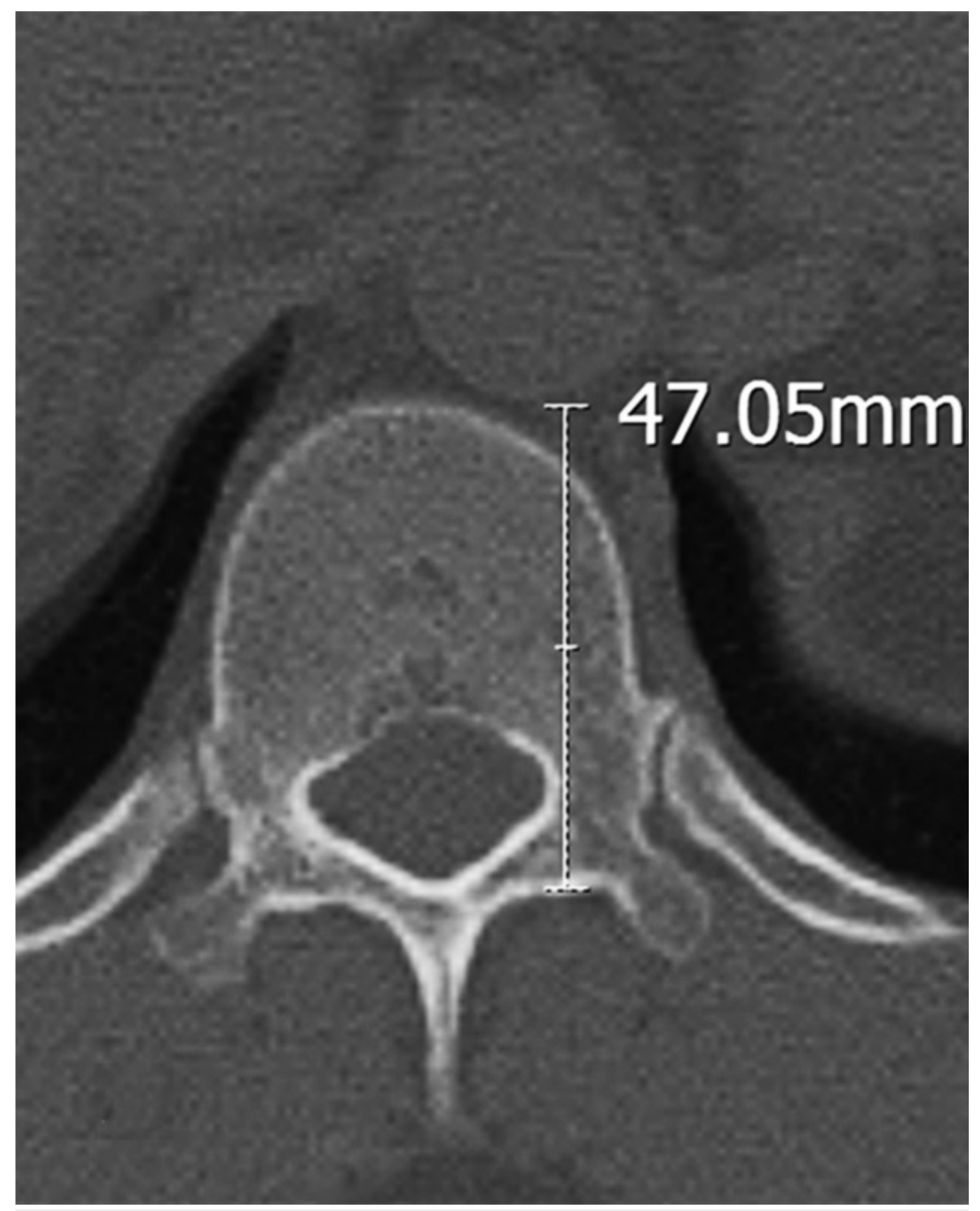

FIGURE 1: T12 pedicle axial transverse section in a male. The distance between the screw entry point and the thoracic aorta. 


\section{Cureus}

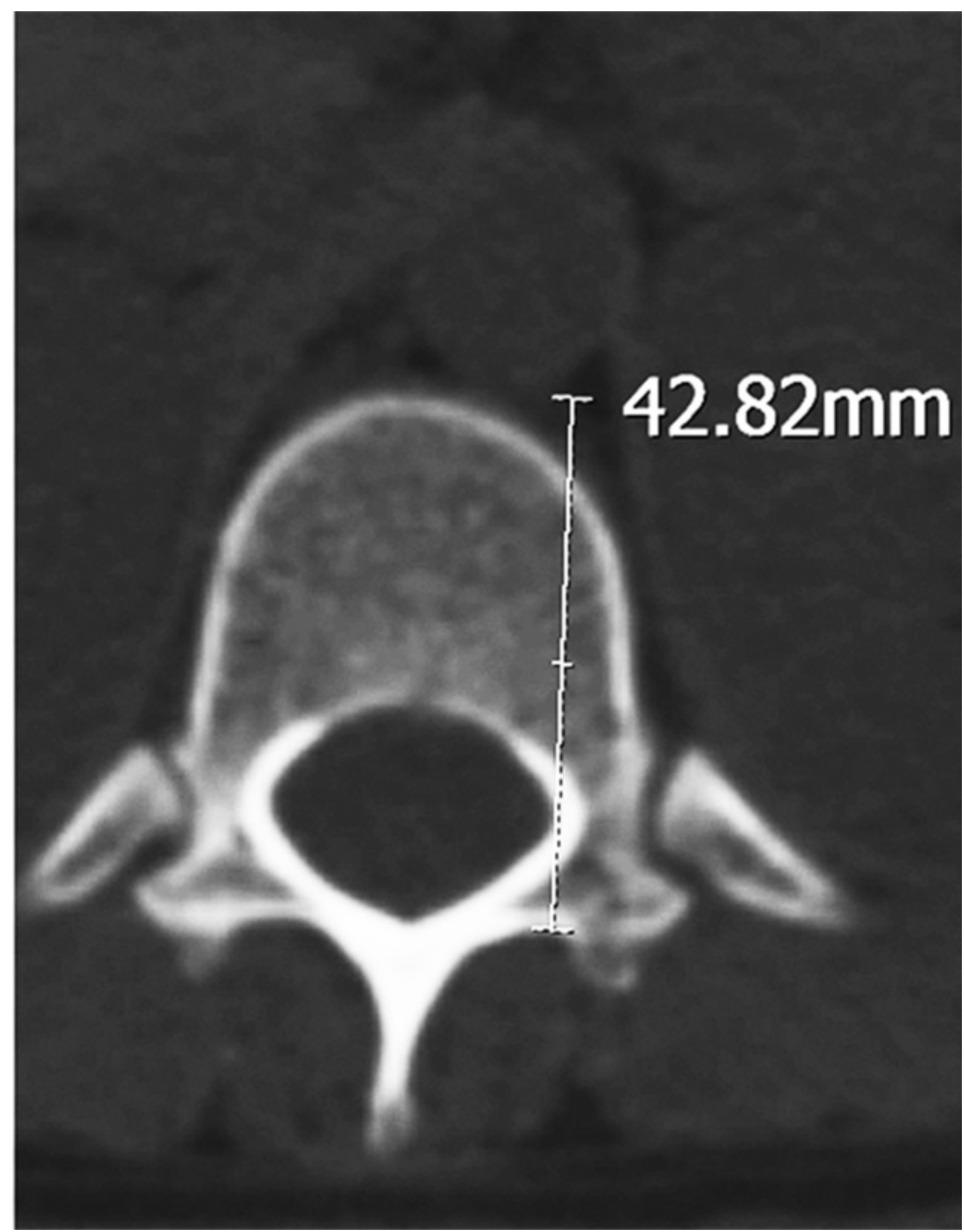

FIGURE 2: T12 pedicle axial transverse section in a female. The distance between the screw entry point and the thoracic aorta.

For the closest distance between the T12 vertebral body and the aorta, the measurement of the closest distance between the anterior of the T12 vertebral body and the thoracic aorta was made (Figure 3 and Figure 4). 


\section{Cureus}

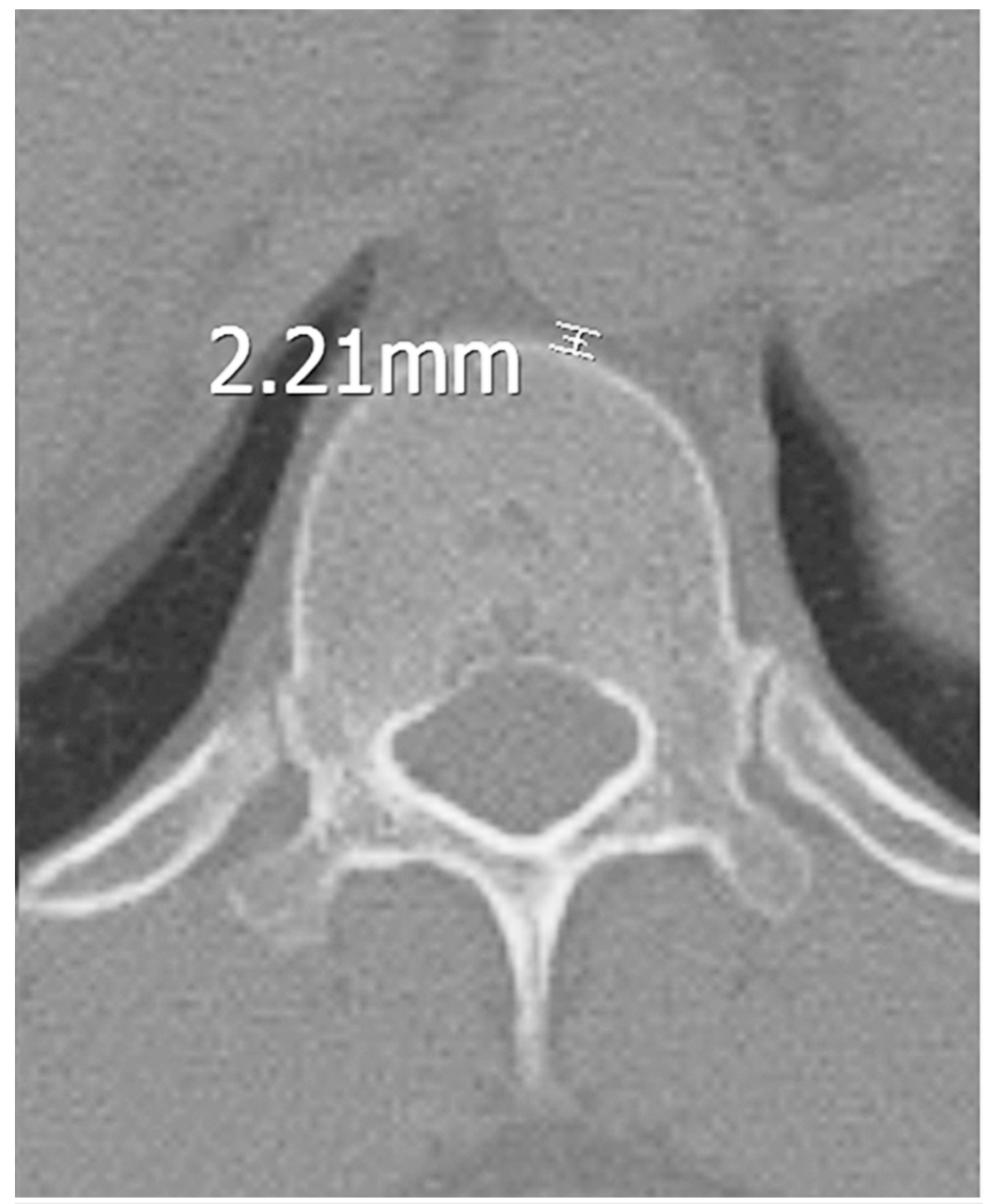

FIGURE 3: T12 pedicle axial transverse section in a male. The distance between the anterior vertebral body and the thoracic aorta. 


\section{Cureus}

\section{$1.26 \mathrm{~mm} \geqslant$}

FIGURE 4: T12 pedicle axial transverse section in a female. The distance between the anterior vertebral body and the thoracic aorta.

All data were input into Microsoft Excel and analyses were made using the SPSS software (IBM, Armonk, New York, United States). The measurement results were expressed as mean ${ }^{ \pm}$standard deviation (SD) and range of values. Statistical analyses were performed with the student's t-test and Pearson's correlation coefficient and using the PASW Statistics v.18 software (IBM, Armonk, New York, United States).

\section{Results}

A statistically significant difference was detected in the distance from the T12 left screw entry point to the aorta between males and females. The distance in the males was $47.12 \pm 3.38$ (range: 


\section{Cureus}

40.01 to 54.00$) \mathrm{mm}$ and in the females, it was $43.70 \pm 3.00$ (range: 37.99 to 49.26$) \mathrm{mm}(\mathrm{p}=0.001)$

(Table 1).

\begin{tabular}{|c|c|c|c|c|c|c|}
\hline & Gender & $\mathbf{N}$ & Mean & SD & Min-Max & $\mathbf{p}$ \\
\hline \multirow{2}{*}{ Distance between the left screw entry point-aorta $(\mathrm{mm})$} & Male & 30 & 47.12 & 3.38 & \multirow{2}{*}{$37.99-54.00$} & \multirow{2}{*}{0.001} \\
\hline & Female & 30 & 43.70 & 3.00 & & \\
\hline
\end{tabular}

\section{TABLE 1: Comparison of the data of the distance between the left screw entry point} and the aorta according to gender.

No statistically significant correlation was found between age (31.93 \pm 3.91 (range: 25 to 40 ) years) and the distance between the left screw entry point and the aorta $(45.41 \pm 3.61$ (range: 37.99 to 54.00$) \mathrm{mm})(\mathrm{p}=0.105)$ (Table 2).

\begin{tabular}{|c|c|c|c|c|c|}
\hline & $\mathbf{N}$ & Mean & SD & Min-Max & $\mathbf{p}$ \\
\hline Age & 60 & 31.93 & 3.91 & $25-40$ & \multirow{2}{*}{0.105} \\
\hline Left screw entry point-aorta shortest distance (mm) & 60 & 45.41 & 3.61 & $37.99-54.0$ & \\
\hline
\end{tabular}

\section{TABLE 2: Comparison of the data of age and the shortest distance between the left} screw entry point and the aorta.

Also, no statistically significant difference was detected between the T12 vertebral body-aorta distance in males $(1.77 \pm 0.55$ (range: 0.78 to 3.16$) \mathrm{mm}$ ) and in females (1.94 \pm 0.52 (range: 1.02 to 3.56) $\mathrm{mm})(\mathrm{p}=0.212)$ (Table 3).

\begin{tabular}{|l|l|l|l|l|l|l|}
\hline & Gender & N & Mean & SD & Min-Max & p \\
\hline Aorta-corpus shortest distance $(\mathrm{mm})$ & Male & 30 & 1.77 & 0.55 & $0.78-3.56$ & 0.212 \\
\hline & Female & 30 & 1.94 & 0.52 &
\end{tabular}

TABLE 3: Comparison of the data of the shortest distance between the T12 corpus and the aorta according to gender.

The relationship between the shortest aorta-vertebral body distance ( $1.85 \pm 0.54$ (range: 0.78 to $3.56) \mathrm{mm}$ ) and age (31.93 \pm 3.91 years (range: 25 to 40 ) years) was not statistically significant $(\mathrm{p}=0.7)($ Table 4). 


\section{Cureus}

\begin{tabular}{|l|l|l|l|l|l|}
\hline & N & Mean & SD & Min-Max & $\mathbf{p}$ \\
\hline Age & 60 & 31.93 & 3.91 & $25-40$ & \\
T12 corpus-aorta shortest distance $(\mathrm{mm})$ & 60 & 1.85 & 0.54 & $0.78-3.56$ & 0.70 \\
\hline
\end{tabular}

TABLE 4: Comparison of the data of age and the shortest distance between the T12 corpus and the aorta.

Similarly, there was no statistically significant difference between the left screw entry pointaorta distance ( $45.41 \pm 3.61$ (range: 37.99 to 54.00$) \mathrm{mm}$ ) and the aorta-vertebral body shortest distance ( $(1.85 \pm 0.54$ (range: 0.78 to 3.56$) \mathrm{mm})(\mathrm{p}=0.731)$ (Table 5).

\begin{tabular}{|l|l|l|l|l|l|}
\hline & N & Mean & SD & Min-Max & p \\
\hline Aorta-corpus shortest length & 60 & 1.85 & 0.54 & $0.78-3.56$ & \\
\hline Left screw entry point-aorta shortest distance $(\mathrm{mm})$ & 60 & 45.41 & 3.61 & $37.99-54.0$ & \\
\hline
\end{tabular}

TABLE 5: Comparison of the data of the shortest distance between the T12 corpus and the aorta and the shortest distance between the left screw entry point and the aorta.

\section{Discussion}

Pedicle screw stabilization in the thoracic region is a widely used method applied in the treatment of several pathologies, such as degenerative diseases, deformities, tumor, and traumatic instability. Knowledge of the vertebral body and pedicle morphology provides great advantages to the surgeon in the application of the pedicle screw during surgery.

During spinal instrumentation, the surgeon must decide on the screw length and its path to obtain the strongest fixation without damaging the neurological and vascular structures adjacent to the pedicle and vertebral body. The ideal techniques for screw advancement are obvious, however, the surgeon generally makes the decision of appropriate thickness and length of screw based on previous experience. When compared to the lumbar vertebra, the placement of the thoracic pedicle screw is more difficult due to its small size, varying entry points, and proximity to neurovascular structures and the spinal cord [5]. Any kind of major deviation causing the perforation of the pedicle or vertebral cortex may lead to neurological and vascular damage. In addition, the entry depth of the screw in the axial plane must be checked. Rates of intraoperative pedicle and/or vertebral body perforations during pedicle screw placement have been reported in the literature, ranging from $5.5 \%$ to $39.9 \%$ [6-7].

The ideal pedicle screw should have the maximum diameter and length that will not impinge on the pedicle cortical layer and the vertebral body [8]. Recently, there has been an increase in studies regarding the correct placement of screws in spinal surgery [9-13]. In a meta-analysis of 130 studies by Kosmopoulos and Schizas, the authors found out that out of 37,337 pedicle 
screws, a mean of $8.7 \%$ was incorrectly placed [14]. The risk of incorrect placement can be reduced with excellent anatomic knowledge, attention paid to all anatomical marks, careful evaluation of preoperative imaging, and the use of modern equipment during surgery.

Attention should be paid to the azygos vein, the intercostal arteries, the vena cava inferior, and the aorta, all of which are at risk during the placement of pedicle screws in the thoracic region. Vanichkachhorn et al. reported cases of major vascular injury, which developed following the removal of incorrectly placed screws in the thoracolumbar region [15]. This case inspired a comprehensive evaluation before the removal of incorrectly oriented screws. Lopera et al. presented a series of six cases with seven artery injuries related to incorrectly applied screw fixation systems in the thoracic region [16].

Computed tomography is the easiest method that gives the most accurate results in the evaluation of vertebral morphometry. Therefore, the majority of studies examining screw pedicle compatibility have used CT scanning, as in the current study [17-19]. The measurements made in this study to determine the appropriate screw length for the T12 vertebra are important with respect to preventing major vascular and vital organ injuries related to anterior cortex perforation. Foxx et al. found that 33 of 680 screws placed in the thoracolumbar area were in contact with major blood vessels, and no symptoms or sequelae associated with vascular contact were observed [20]. However, other authors have emphasized that where a screw is in contact with a blood vessel and continually striking it, a secondary lesion (lacerations or pseudoaneurysms) may develop in the area of contact, and a revision surgery will be necessary [21]. Therefore, preoperative determination of appropriate screw length prevents the risk of anterior cortex perforation and major vascular injuries.

This study shows the importance of the length and safety of T12 pedicle screws, evaluates the average values of pedicle screw length, and increases awareness of it. But, the length of the pedicle screws should be measured in the patient's CT images or plain X-ray before surgery and determined based on the morphology of each patient. This is the major limitation of our study.

\section{Conclusions}

In conclusion, regardless of the technique applied, pedicle-screw-based instrumentation is a strong fixation method for the thoracolumbar spine. When placing the pedicle screw in the T12 vertebra, the length of the screw is just as important as the screw entry point and orientation. Therefore, preoperative radiological planning and distance measurement will reduce iatrogenic vascular injuries.

\section{Additional Information Disclosures}

Human subjects: Consent was obtained by all participants in this study. Animal subjects: All authors have confirmed that this study did not involve animal subjects or tissue. Conflicts of interest: In compliance with the ICMJE uniform disclosure form, all authors declare the following: Payment/services info: All authors have declared that no financial support was received from any organization for the submitted work. Financial relationships: All authors have declared that they have no financial relationships at present or within the previous three years with any organizations that might have an interest in the submitted work. Other relationships: All authors have declared that there are no other relationships or activities that could appear to have influenced the submitted work.

\section{References}

1. Roy-Camille R, Saillant G, Mazel C: Internal fixation of the lumbar spine with pedicle screw 
plating. Clin Orthop Relat Res. 1986, 203:7-17.

2. Weinstein JN, Spratt KF, Spengler D, Brick C, Reid S: Spinal pedicle fixation: reliability and validity of roentgenogram-based assessment and surgical factors on successful screw placement. Spine (Phila Pa 1976). 1989, 14:1012-1218.

3. Esses SI, Sachs BL, Dreyzin V: Complications associated with the technique of pedicle screw fixation. A selected survey of ABS members. Spine (Phila Pa 1976). 1993, 18:2231-2238.

4. Ghobrial GM, Maulucci CM, Maltenfort M, et al.: Operative and nonoperative adverse events in the management of traumatic fractures of the thoracolumbar spine: a systematic review. Neurosurg Focus. 2014, 37:8. 10.3171/2014.4.FOCUS1467

5. McCormack BM, Benzel EC, Adams MS, Baldwin NG, Rupp FW, Maher DJ: Anatomy of the thoracic pedicle. Neurosurgery. 1995, 37:303-308.

6. Steinmann JC, Herkowitz HN, El-Kommos H, Wesolowski P: Spinal pedicle fixation: confirmation of an image-based technique for screw placement. Spine (Phila Pa 1976). 1993, 18:1856-1861.

7. Gertzbein SD, Robbins SE: Accuracy of pedicular screw placement in vivo . Spine (Phila Pa 1976). 1990, 15:11-14.

8. Cho W, Cho SK, Wu C: The biomechanics of pedicle screw-based instrumentation. J Bone Joint Surg Br. 2010, 92:1061-1065. 10.1302/0301-620X.92B8.24237

9. Kantelhardt SR, Martinez R, Baerwinkel S, Burger R, Giese A, Rohde V: Perioperative course and accuracy of screw positioning in conventional, open robotic-guided and percutaneous robotic-guided, pedicle screw placement. Eur Spine J. 2011, 20:860-868. 10.1007/s00586-0111729-2

10. Kotil K, Bilge T: Accuracy of pedicle and mass screw placement in the spine without using fluoroscopy: a prospective clinical study. Spine J. 2008, 8:591-596.

10.1016/j.spinee.2007.04.002

11. Nottmeier EW, Seemer W, Young PM: Placement of thoracolumbar pedicle screws using threedimensional image guidance: experience in a large patient cohort. J Neurosurg Spine. 2009, 10:33-39. 10.3171/2008.10.SPI08383

12. Tian NF, Xu HZ: Image-guided pedicle screw insertion accuracy: a meta-analysis . Int Orthop. 2009, 33:895-903. 10.1007/s00264-009-0792-3

13. Verma R, Krishan S, Haendlmayer K, Mohsen A: Functional outcome of computer-assisted spinal pedicle screw placement: a systematic review and meta-analysis of 23 studies including 5992 pedicle screws. Eur Spine J. 2010, 19:370-375. 10.1007/s00586-009-1258-4

14. Kosmopoulos V, Schizas C: Pedicle screw placement accuracy: a meta-analysis. Spine (Phila Pa 1976). 2007, 32:111-120. 10.1097/01.brs.0000254048.79024.8b

15. Vanichkachorn JS, Vaccaro AR, Cohen MJ, Cotler JM: Potential large vessel injury during thoracolumbar pedicle screw removal. A case report. Spine (Phila Pa 1976). 1997, 22:110-113.

16. Lopera JE, Restrepo CS, Gonzales A, Trimmer CK, Arko F: Aortoiliac vascular injuries after misplacement of fixation screws. J Trauma. 2010, 69:870-875. 10.1097/TA.0b013e3181f0bd55

17. Bernard TN, Seibert CE: Pedicle diameter determined by computed tomography: its relevance to pedicle screw fixation in the lumbar spine. Spine (Phila Pa 1976). 1992, 17:160-163.

18. Zindrick MR, Wiltse LL, Widell EH, Thomas JC, Holland WR, Field BT, Spencer CW: A biomechanical study of intrapedicular screw fixation in the lumbosacral spine. Clin Orthop Relat Res. 1986, 203:99-112.

19. Krag MH, Beynnon BD, Pope MH, Frymoyer JW, Haugh LD, Weaver DL: An internal fixator for posterior application to short segments of the thoracic, lumbar, or lumbosacral spine: design and testing. Clin Orthop Relat Res. 1986, 203:75-98.

20. Foxx KC, Kwak RC, Latzman JM, Samadani U: A retrospective analysis of pedicle screws in contact with the great vessels. Clinical article. J Neurosurg Spine. 2010, 13:403-406. 10.3171/2010.3.SPINE09657

21. Gautschi O P, Schatlo B, Schaller K, Tessitore E: Clinically relevant complications related to pedicle screw placement in thoracolumbar surgery and their management: a literatüre review of 35,630 pedicle screws. Neurosurg Focus. 2011, 31:8. 10.3171/2011.7.FOCUS11168 